\title{
Introduction of GIS software (Geographical information system) as a life Teachers and Students / imedium School for Namira Medan
}

\author{
Emilia Kadreni ${ }^{1 *}$, Ahmad $^{2}$, Indra ${ }^{1}$, Hamidah $^{2}$, Renita $^{2}$ \\ ${ }^{1}$ Dosen Teknik Sipil, Fakultas Teknik, Universitas Sumatera Utara \\ ${ }^{2}$ Dosen Teknik Kimia, Fakultas Teknik, Universitas Sumatera Utara \\ Email*: emiliakadreni@gmail.com
}

\begin{abstract}
Namira High School is one of the favorite schools in the city of Medan, with the number of students graduating and being accepted at the State University increasing from year to year. To further foster and improve the quality and creativity of Namira High School Students and Teachers, a technology-based training program for the Geographical Information System (GIS). Community Service Program is part of the Tri Dharma College, in collaboration with High School partners Namira, is expected to be able to increase learning in the Computer Laboratory to learn the concepts and technology of GIS which is relatively new. By attending this training, students get the opportunity to work more by utilizing geospatialbased information. The use of Geographical Information System (GIS) in various fields is very real, because GIS provides various facilities that are relatively easy to do. With the open source GIS software training, it is hoped that students and teachers at Namira High School will know the importance of geography literacy and its use in various fields.
\end{abstract}

Keyword: Waste, carbide welding, compressive strength, concrete, high quality, optimization

\begin{abstract}
Abstrak
Sekolah Menegah Atas Namira merupakan salah satu sekolah favorit di kota Medan, dengan jumlah siswa yang lulus dan diterima di Pergurun Tinggi Negeri yang meningkat dari tahun ke tahun. Untuk lebih menumbuhkan dan meningkatkan kualitas dan kreatifitas Siswa serta Guru Sekolah Menengah Atas Namira, diadakan pelatihan berbasis teknologi Program Geographical Information System (GIS).Program Pengabdian kepada Masyarakat yang merupakan salah satu bagian dari Tri Dharma Perguruan Tinggi, bekerja sama dengan mitra Sekolah Menengah Atas Namira, diharapkan dapat lebih menigkatkan pembelajaran di Laboratorium Komputer untuk mempelajari konsep dan teknologi GIS yang relative masih baru. Dengan mengikuti pelatihan ini, para siswa memperoleh kesempatan untuk lebihberkarya dengan memafaatkan informasi yang berbasis geospasial.Pemanfaatan Geographical Information System (GIS) dalam berbagai bidang sangat nyata, dikarenakan GIS memberikan berbagai fasilitas yang relative mudah untuk dilakukan. Dengan adanya pelatihan software GIS yang open source, diharapkan siswa dan guru Sekolah Menengah Atas Namira mengetahui pentingnya literasi geografi dan penggunaannya dalam berbagai bidang
\end{abstract}

Kata Kunci : Limbah, las karbit, kuat tekan, beton, mutu tinggi, optimalisasi 


\section{PENDAHULUAN}

\subsection{Analisis Situasi}

Perkembangan bidang teknologi khususnya system informasi geografi akhir - akhir ini sangatlah berpotensi untuk memberikan manfaat yang besar bagi masyarakat termasuk dalam dunia pendidikan. Potensi pengetahuan teknologi system informasi geografis pada jenjang pendidikan sekolah sangatlah membantu memberikan kontribusi dalam percepatan pengetahuan serta motivasi untuk menempuh pendidikan yang lebih tinggi maupun dalam dunia kerja.

Pelatihan maupun penyelenggaraan pembelajaraan ini menjadi focus utama sehingga dapat membantu siswa SMA untuk memperdalam ilmu teknologi dan dapat membantu dalam pengembangan pengetahuan dalam tingkat menengah. Umumnya agar siswa lebih siap untuk ikut berkontribusi dalam perkembangan teknologi Sistem Informasi Geografi dan berkontribusi untuk bangsa dan negaranya.

Pemilihan Sekolah Menengah Atas (SMA) Namira merupakan sasaran yang sangat dibutuhkan disebabkan dengan adanya pelatihan yang dimaksud terkhusus bagi siswa/I yang sedang menjalankan pendidikan, sehingga memberikan manfaat dalam mengembangkan kemampuan serta pengetahuan yang sudah di dapatkan dari sekolah tersebut.

Kegiatan ini merupakan salah satu bentuk kepedulian Lembaga Pengabdian Keapada Masyarakat dalam mencerdaskan kehidupan bangsa. Kegiatan pelatihan ini sangat diperlukan bagi siswa/I dalam mendapatkan pengetahuan baru sehingga memberikan kesempatan untuk mempelajari maupun mengetahui sejak dini kemampuan iptek dalam pembangunan teknologi informasi geospasial di dalam Negara Indonesia.

Oleh karena itu dibutuhkan semangat cinta tanah air dan kreatifitas untuk membangun Indonesia yang lebih sejahtera. Dalam pelaksanaannya siswa SMU masih membutuhkan bimbingan dan arahan untuk megetahui dasar - dasar permasalahan dan langkah - langkah penyelesaian masalah tersebut. Denan beberapa bekal materi dan ilmu pengetahuan yang diberikan kepada siswa tersebut dihrapkan lebih memiliki motivsi untuk mempelajari cara - cara mengembangkan dan menangani penyelesaian masalah - masalah lingkungan dan ikut serta memberikan kontribusi secara nyata keapda masyarakat.

\subsection{Permasalahan Mitra}

Banyak permasalahan di berbagai bidang kehidupan mmerlukan informasi dan analisis terkait geospasial (keruagnan). Konsep dan teknologi GIS memberikan salah satu solusi terbaik dalam pemecahannya. Agar hal ini dapat dikuasai secara optimal, maka para siswa sekolah perlu memperoleh pengenalan tentang GIS sejak di bagku sekolah.

Program pelatihan ini membantu siswa SMA untuk mengetahui kemajuan ilmu pengetahuan dan teknologi khususnya teknologi system informasi geografi yang merupakan salah satu teknologi yang sedang menjadi topic yang penting dalam menyelesaikan permasalahan permasalahan terkait system informasi berbasis geospasial. Pelatihan ini diharapkan dapat menjadi penunjang kemajuan dalam bidang pendidikan di Indonesia.

\subsection{Tujuan}

Adapun tujuan dari kegiatan Pengabdian Kepada Masyarakat ini adalah memperkenalkan kepada Guru dan Siswa sekolah menegah umum tentang pentingnya literasi geografi dan teknologi GIS, dengan kompetensi :

1. Guru dan siswa dapat memahami dasar - dasar GIS

2. Guru dan siswa dapat mengakses informasi berbasis spasial dengan teknologi GIS

3. Guru dan siswa dapatmulai memanfaatkan teknologi GIS untuk memecahkan masalah yang terkait informasi geospasial

4. Guru dan siswa lebih mengenal dengan perangkat lunak GIS yang open source 


\subsection{Manfaat}

Manfaat yang dapat diperoleh dari kegiatan Pengabdian Kepada Masyarakat ini adalah :

1. Memberikan Pelatihan dan pegnalaman yang bernilai tinggi terkait kemajuan ilmu teknologi khususnya di sekolah

2. Meningkatkan semangat siswa/I untuk belajar sehingga termotivasi untuk melanjutkan pendidikan hingga ke Perguruan Tinggi

3. Memberi bekal keapada para siswa untuk sadar dan bergerak memanfaatkan teknologi GIS untuk pengelolaan informasi geospasial

\subsection{Solusi yang Ditawarkan}

Berdasarkan permasalahan yang dihadapi oleh mitra kerjasama yang sudahdisepakati, selama ini para guru dan siswa di Sekolah Menengah Atas Namira belum mengenal dan memanfaatkan teknologi GIS untuk memecahkan masalah yang terkait informasi geospasial

Diaharapkan dengan adanya pelatihan GIS, para guru dan siswa dapat mengakses informasi berbasis spasial dengan teknologi GIS sehingga memudahkan dalam pengerjaan tugas - tugas yang berhubungan dengan teknologi GIS.

\subsection{Target Luaran}

Target yang diharapkan adalah :

1. Guru dan siswa dapat mandiri mencari solusi serta menyelesaikan permasalahan mengenai system informasi berbasis geospasial

2. Memberikan kesempatan untuk guru dan siswa mengembangkan teknologi system informasi geografi berbasis geospasial baik hanya dalam membuat peta untuk mendukung kegiatan belajar siswa amupun analisis spasial yang lebih lanjut.

3. Guru dan siswa mendapatkan keilmuan baru dan lebih termotivasi untuk bersama - sama membangun daerah - daerah terpencil yang membutuhkan sousi atau langkah - langkah konkrit.

4. Menjadikan guru dan siswa yang lebih kompetitif terhadap kemajuan teknologi bidang system informasi geografi sehingga menjadikan Indonesia dapat erasing dengan Negara lainnya dalam bidang teknologi terbaru.

5. Memberikan kesempatan keapada para guru dan siswa untuk berkontribusi dan berani bersaing dalam bidang kelimuan teknologi geospasial

Luaran wajib yang ditargetkan Program pengabdian Masyarakat Mono Tahun Reguler berupa :

1. Satu artikel ilmiah yang dipublikasikan melalui Jurnal ber ISSN atau prosiding dariseminar nasional;publikasi pada media masa cetak/online/repocitory PT;

2. Video Kegiatan

3. Peningkatan daya saing dengan sekolah menengah atas lainnya

4. Peningkatan penerapan iptek di masyarakat (mekanisasi, IT, dan manajemen)

5. Pemanfaatan software GIS untuk menyelesaikan permasalah yang berhubungan denga pemetaan

6. Perbaikan tata nilai masyarakat (seni budaya, sosial, politik, keamanan, ketentraman, pendidikan, kesehatan)

\subsection{Pengenalan Program Geographical Information System (GIS).}

Penyuluhan awal dilakukan perkenalan dan memberikan pengertian awal tentang Program Geographical Information System (GIS). dan aplikasi penggunaan. Perlu adanya pengenalan Program Geographical Information System (GIS) bagi siswa/I Sekolah Menengah Atas Namira yang awam mengenai program computer (software) tersebut. Pengenalan Program GIS di sampaikan oleh Bapak Dr. Ir. Ahmad Perwira Mulia, MSc.

Penyuluhan awal ini memiliki target sasaran:Siswa/I kelas XI Sekolah Menengah Atas Namira Medan mengetahui tentang Penyuluhan awal dilakukan perkenalan dan memberikan 
pengertian awal tentang Program Geographical Information System (GIS). dan aplikasi penggunaannya.

\subsection{Pelaksanaan Pelatihan dan Latihan Mandiri}

Dikarenakan jumlah peserta yang melebihi target yang di rencanakan semula 40 orang peserta menjadi 75 orang peserta ( terdiri atas siswa/I 2 buah kelas XI ditambah guru) maka pelatihan di bagi dalam 2 sesi dimana jumlah peserta di bagi 2 , untuk memudahkan para sisw/I menyerap ilmu yang diajarkan, serta memudahkan dalam melaksanakan latihan mandiri.

Pada tahap ini, siswa/I diwajibkan untuk melakukan kegiatan latihan mandiri dalam penggunakan Program GIS untuk lebih pengembangan system informasi geografi lebih lanjut. Latihan ini dilakukan dengan cara mengerjakan suatu kasus dan menemukan solusi dari permasalahan tersebut.

\section{METODE PELAKSANAAN}

\subsection{Prosedur Kegiatan}

Untuk memperoleh manfaat yang maksimal sebagai mana diharapkan, maka kegiatan yang dilaksanakan dalam beberapa kali kunjungan ke tempat mitra yaitu Sekolah Menengah Atas Namira, dengan rangkaian beberapa kegiatan yang meliputi :

1. Koordinasi dengan kepala Sekolah Menengah atas Namira mengenai teknis pelaksanaan kegiatan 2. Melakukan identifikasi permasalahan masyarakat di lokasi pengabdian berkaitan dengan peningkatan mutu pendidikan dengan cara meningkatkan keterampilan pemanfaatan computer di Sekolah Menengah Atas Namira Medan

3. Pelaksanaan pengabdian masyarakat dalam bentuk presentasi modul dan melakukan praktek langsung menggambar menggunakan Program Geographical Information System (GIS)

4. Tanya jawab langsung (diskusi) antara pemateri dengan siswa/I kelas XI Sekolah Menengah Atas Namira.

5. Evaluasi keberhasilan pelaksanaan pengabdian masyarakat bagi siswa/I siswa/I kelas XI Sekolah Menengah Atas Namira.

\subsection{Kegiatan Pengabdian}

Pelaksanaan kegiatan berupa pelatihan Program Geographical Information System (GIS) yang di lakukan oleh beberapa orang pemateri dan pendamping lain bagi siswa/I kelas XI Sekolah Menengah Atas Namira. Target sasaran kegiatan pemberian modul Program Geographical Information System (GIS) dan snack dan makan siang sebagai sarana pendukung. Setelah pemberian modul dan pelatihan diadakan evaluasi bagi siswa/I untuk mengetahui sampai sejauh mana siswa/I memahami Program Geographical Information System (GIS). Untuk 3 orang siswa/i yang dapat menyelesaikan tugas tercepat dan benar akan diberikan reward atau penghargaan berupa hadiah satu buah flashdisk.

\subsection{Lokasi Kegiatan}

Lokasi Dan Waktu Kegiatan

Kegiatan Pengabdian kepada Masyarakat dilaksanakan pada :

Hari /Tanggal Kegiatan : Rabu, 20 November 2019

Lokasi kegiatan :Ruang kelas XI Sekolah Menengah Atas Namira

Jalan Setia Budi Pasar 1 No. 76 Tanjung Sari Medan

\subsection{Pemateri dan Bahan}

Pemateri yang dilibatkan dalam kegiatan pengabdian ini adalah dosen dan mahasiswa asisten Departemen Teknik Sipil Fakultas Teknik Universitas Sumatera Utara. Mahasiswa yang berperan 
sebagai pemateri adalah Hasanul Arifin Purba dan Tesar Rizky P Nasution, yang meruapakan mahasiswa Magister Teknik Sipil sudah mempunyai berpengalaman menggunakan aplikasi GIS.

Sedangkan sebagai dosen pemateri adalah Bapak : Dr. Ir. Ahmad Perwira Mulia, MSc sebagai ketua Program Studi S2/S3 Departemen Teknik Sipil Universitas Sumatera Utara.

Setiap Siswa/I kelas XI Sekolah Menengah Atas Namira mendapatkan sebuah Goodie bag yang berisikan antara lain

\begin{tabular}{cl} 
yang berisikan antara lain & Satuan \\
\hline Isi Goodie Bag & 1 Buah
\end{tabular}

software Program Geographical

1 Buah

Information System (GIS)

Notes 1 Buah

Ballpoint 1 Buah

Tabel 2.1 Tabel Isi Goodie Bag

\subsection{Persiapan Materi Pelatihan}

Setelah berkoordinasi dengan pihak mitra, yaitu Sekolah menengah Atas Namira yang di wakili oleh kepala sekolah, perlu adanya persiapan materi Pelatihan Program Geographical Information System (GIS) berupa modul dan bahan presentasi. yaitu :

Materi Program Geographical Information System (GIS) yang terdapat Modul Pelatihan

Bab I Pengenalan fasilitas sederhana dan tools dasar pada QGIS

1.1. Membuka Data Peta Vektor pada QGIS

1.2. Fasilitas Pengukur Jarak dan Luas

1.3. Identify Features

1.4. Attribute Table

Bab II Pengolahan Peta TEmatik

2.1. Menghitung Panjang Garis

2.2. Menghitung Panjang Jalan

2.3. Menghitung Banyaknya Data Titik pada Suatu Area

Bab III Membuat Layout Peta

Modul yang terdiri atas 37 halaman tersebut diperbanyak dan dibagikan kepada seluruh peserta pelatihan. Dalam modul tersebut para siswa/I di pandu secara bertahap untuk dapat menjalankan program Geographical Information System (GIS), lengkap dengan tampilan gambar yang tersedia pada Program Geographical Information System (GIS).

\section{HASIL DAN PEMBAHASAN}

\subsection{Analisis Kegiatan Pengabdian Kepada Masyarakat}

a. Faktor Penghambat

Dalam pelaksanaan kegiatan pengabdian kepada masyarakat ini,tidak ditemukan kendala yang signifikan. Dengan tim pelaksana yang solid, dengan bertambahnya jumlah peserta tidak mengurangi tujuan pelaksanaan kegiatan pengabdian kepada masyarakat.Hal yang 
perlu diperhatikan adalah waktu yang disediakan masih kurang cukup mengingat masih bayak lagi materi lebih lanjut yang belum bisa diberikan.

b. Faktor Pendorong

Di era yang serba digital saat ini, penggunaan Program Geographical Information System (GIS) yang berbasis peta sangat di butuhkan dalam kehidupan sehari - hari, hal ini yang mendorong rasa antuisme dari para siswa/I Sekolah Menengah Atas peserta Pelatihan Geographical Information System (GIS) mengikuti kegiatan ini dengan tekun. Hal ini memudahkan penggunaan aplikasi yang berbasis peta yang sudah terlebih dahulu popular dimasyarakat, seperti google map.

Hal ini diharapkan sesuai dengan tujuan yang akan dicapai oleh tim pelaksana yaitu melalui kegiatan ini siswa/I dapat mengoperasikan dan mengaplikasikan Program Geographical Information System (GIS).sehingga dapat meningkatkan daya kreativitas siswa/i.

\section{KESIMPULAN}

Dari Kegiatan Pengabdian Kepada Masyarakat berupa pelatihan Program Geographical Information System (GIS) bagi siswa/I kelas XI sangat membantu dalam meningkatkan keterampilan pemanfaatan computer, memahami lebih dalam Program Geographical Information System (GIS). dan mengaplikasikan dengan menuangkan ide dan gagasan dalam bentuk gambar, sehingga meningkatkan daya kreativitas para siswa.

\section{UCAPAN TERIMAKASIH}

Tim pelaksana kegiatan pengabdian kepada masyarakat mengucapkan terima kasih kepada Lembaga Pengabdian Kepada Masyarakat USU yang telah mendanai kegiatan ini melalui skim pengabdian Mono Tahun Dosen Muda dengan sumber dana Non PNBP Universitas Sumatera Utara.

\section{DAFTAR PUSTAKA}

Renganathan E, et al,. Towards Sustaining Behavioural Impact in Dengue Prevention and Control. Dengue Bulletin. 2003;27

Roberto. Tapia-conyer, Méndez-galván J, Burciagazúñiga P, et al. Paediatrics and International Child Health Community participation in the prevention and control of dengue : the patio limpio strategy in Mexico Community participation in the prevention and control of dengue : the patio limpio strategy in Mexico. $2013 ; .32$ ( S 1): $10-13$ doi:10.1179/2046904712Z.00000000047. Retrieved from https://www.ncbi.nlm.nih.gov/pmc/art icles/PMC3381439/

Breilh J, Spiegel J, Wilches AA, Mitchell- foster K, Delgado JA. Integrating participatory community mobilization processes to improve dengue prevention : an eco-bio-social scaling up of local success in. Journal Transactions of The Royal Society of Tropical medicine and Hygie ne. 1092015.: 126 - 133. doi:10.1093/trstmh/tru209 